\title{
Avaliação dos programas de treinamento e mapeamento de competências em uma serventia prestadora de serviços públicos com administração privada
}

\author{
Evaluation of training programs and mapping skills on a provider \\ usefulness of public services with private management
}

\begin{abstract}
Resumo
O presente trabalho objetivou avaliar os programas de treinamento e desenvolvimento implantados no $1^{\circ}$ Oficial de Registro de Imóveis, Títulos e Documentos e Civil de Pessoa Jurídica de Piracicaba e mapear as competências desenvolvidas através dos treinamentos aplicados dentro da instituição prestadora de serviços públicos. Para tal, foi realizada uma pesquisa bibliográfica sobre as áreas de registro imobiliário, treinamento, desenvolvimento e competências, sob a finalidade de identificar e reunir conceitos aplicáveis ao estudo. Utilizou-se também para coletar dados um questionário. Os resultados mostram que diante dos treinamentos aplicados houve o desenvolvimento das competências técnicas dos colaboradores, obtendo assim, uma prestação de serviço das atividades do cartório com maior qualidade e maior segurança jurídica aos clientes.
\end{abstract}

Daniela Camolesi ${ }^{1}$ Graziela Oste Graziano $^{2}$

Palavras-chave: Treinamento, Desenvolvimento, Competências.

\begin{abstract}
This study aimed to evaluate the training and development programs implemented on 1st Official Real Estate Registry, Securities and Documents of Legal Entities of Piracicaba and map the competencies developed through training applied within the provider of public services institution. To this end, a literature search on the areas of real estate registration was performed, training, development and skills under the purpose of identifying and gathering concepts applicable to the study. We also used a questionnaire to gather data. The results show that applied before the training was the development of technical skills of employees, thus obtaining a supply of service of the office of the activities with higher quality and greater legal certainty to customers.
\end{abstract}

Keyword: Training, Development, Skills.

\footnotetext{
1 daniela-camolesi@bol.com.br, Brasil. Graduada em Administração pela Faculdade Salesiana Dom Bosco de Piracicaba FSDB. Rua Boa Morte, 1835, Centro, CEP: 13400-140 -Piracicaba, SP - Brasil.

2 graziela.graziano@gmail.com, Brasil. Professora da Universidade Metodista de Piracicaba - UNIMEP. Doutora em Administração pela Universidade Nove de Julho - UNINOVE. Rodovia do Açúcar, km 156, Taquaral, CEP: $13400-000$ -

Piracicaba, SP - Brasil.
} 


\section{Introdução}

Segundo Franco e Corrêa (2OII), o treinamento é um processo da gestão de pessoas que tem como objetivo básico preparar o colaborador para exercer suas funções, desenvolver suas capacidades para o aumento da produtividade e também influenciar nos comportamentos dentro do ambiente de trabalho.

No processo de treinamento e desenvolvimento a avaliação consiste em determinar a efetividade do programa aplicado. Avaliar é uma das partes primordiais do processo e não se pode pensar na mesma como etapa final de um programa de treinamento, pois avaliar deve ser algo contínuo para garantir a eficácia dos programas aplicados.

Ao avaliar programas de treinamento pode-se aferir se o programa foi bem estruturado, se os resultados foram alcançados e se estão trazendo resultados positivos para a organização, até mesmo apresentar a ineficácia do programa desenvolvido ou então a ameaça que trouxe talvez para alguns procedimentos já implantados.

Para Franco e Corrêa (20II), a necessidade de se avaliar um programa de treinamento e desenvolvimento se torna indispensável, uma vez que eles aprimoram o aprendizado dos colaboradores, afetam o comportamento no trabalho e também interferem no resultado financeiro da organização.

É neste contexto que o presente estudo tem o objetivo de avaliar os programas de treinamento e desenvolvimento implantados no $\mathrm{I}^{\circ}$ Oficial de Registro de Imóveis, Títulos e Documentos e Civil de Pessoa Jurídica de Piracicaba e mapear as competências desenvolvidas através dos treinamentos aplicados dentro da instituição prestadora de serviços públicos. Sendo assim, pergunta-se: Como são avaliados os programas de treinamento e desenvolvimento implantados no I Oficial de Registro de Imóveis, Títulos e Documentos e Civil de Pessoa Jurídica de Piracicaba e quais as competências desenvolvidas através dos treinamentos aplicados dentro da instituição prestadora de serviços públicos?

\section{Considerações Gerais sobre Treinamento e Desenvolvimento}

Franco e Corrêa (2OII) comenta que treinamento e desenvolvimento refere-se a um dos recursos essenciais da gestão de pessoas, pois constitui num processo de 
capacitação e qualificação dos colaboradores afim de desenvolver competências que a organização e colaboradores necessitam para se tornarem competitivos e alcançarem suas metas.

É pelo treinamento que o homem se desenvolve profissionalmente, projetando-se socialmente, alavancado pelas melhorias econômicas que consegue como resultado de sua ascensão profissional. Trabalhadores em ascensão, satisfeitos e motivados transformam os ambientes das organizações, deixando-os apropriados para atingir a excelência em termos de desenvolvimento organizacional (MARRAS, 200O, p. I48).

Segundo Boog (1999) o treinamento é uma instituição fundamental na gestão empresarial. Com o crescimento do trabalho especializado, a partir de i88o, o treinamento começou a ser sistematizado, para atender essa nova demanda. Sua articulação como algo racional foi a garantia de atualização dos trabalhadores em suas habilidades, da diminuição de seus erros e da ampliação de sua capacidade para realizar outras tarefas.

Dessler (2003, p.4IO) define o treinamento como “o conjunto de métodos usados para transmitir aos funcionários novos e antigos as habilidades necessárias para o desempenho de treinar enfatizando não o aprendizado em si, mas o conjunto de recursos disponível para transmitir conhecimentos.

Boog (I999) afirma que em consequência da sistematização, a formação profissional generalizou-se como uma necessidade não só da fábrica, mas da sociedade. Em I886 algumas cidades como Chicago, Cleveland, Filadélfia e Baltimore já possuíam escolas dedicadas à capacitação profisssional.

Boog (I999), em paralelo ao sistema educacional, algumas empresas criaram escolas nas próprias fábricas. Em I8722, em Nova Iorque foi fundada uma escola para a formação de maquinistas. A partir de 1930, o treinamento ganhou novo status como atividade administrativa, deixando de ser apenas uma questão operacional ao se tornar parte integral da estratégia empresarial. Nos anos zo, por força da competitividade e da rápida evolução tecnológica, a eficiência dos negócios passou a depender da atualização e aprendizagem do que da autoridade gerencial. Assim, os programas de formação e atualização tornaram-se essenciais para o sucesso dos negócios.

Marras (2000) diz que treinamento prepara o homem para a realização de tarefas específicas, ou seja, é um processo sistemático para promover a aquisição de habilidades, 
regras, conceitos ou atitudes que resultem em uma melhoria da adequação entre as características dos empregados e as exigências dos papéis funcionais.

O desenvolvimento oferece ao treinando uma ampla visão dos negócios, preparando para voos mais altos, a médio e longo prazo, desta forma, aperfeiçoa as capacidades e motiva os funcionários a fim de torná-los futuros membros valiosos da organização. O desenvolvimento inclui não apenas o treinamento, mas também a carreira e outras experiências.

Para Marras (2000, p. I45) treinamento "é um processo de assimilação cultural a curto prazo, que objetiva repassar ou reciclar conhecimentos, habilidades ou atitudes relacionados diretamente à execução de tarefas ou à sua otimização no trabalho”.

O treinamento pode ser entendido como o ato de fornecer os meios para possibilitar a aprendizagem. Complementando com a visão de Chiavenato (2008, p. 404) “aprendizagem é um fenômeno que surge como resultado dos esforços de cada indivíduo. A aprendizagem é uma mudança de comportamento e ocorre no dia-a-dia e em todos os indivíduos".

Para Caldwell (I988) por meio do treinamento é preciso ensinar aos funcionários novas técnicas e comportamentos para que eles possam exercer suas funções. O autor comenta que o desempenho de um funcionário pode estar piorando porque ele esqueceu o método correto para executar uma tarefa.

Segundo Boog (I999) um empregado despreparado ao desempenhar suas tarefas e responsabilidades é fonte de inúmeros problemas como: produtos ou serviços de baixa qualidade, reclamação de clientes, excessiva dependência do supervisor entre outros. Para evitar tais preocupações, sistemas de treinamentos são criados para impedir que empregados despreparados iniciem suas tarefas, evitando assim o trabalho insatisfatório e a baixa motivação.

Boog (I999) o autor diz que a empresa necessita de funcionários bem preparados para realizar corretamente suas tarefas e obter serviços com qualidade. Para isso, o seu pessoal precisa estar bem treinado e motivado. Isso é possível através de programas de treinamento e desenvolvimento fundamentados em algumas premissas básicas:

- Manter estável o quadro de pessoal, especialmente nas atividades-chaves; 
- Controlar profissionais aptos para os cargos disponíveis, mas que possuam escolaridade suficiente para aprendizado rápido e com potencial de desenvolvimento;

- Treinar sistematicamente nas atribuições do cargo e nos procedimentos das operações;

- Retreinar todas as vezes que ocorrerem mudanças nas operações, processos e procedimentos;

- Treinar nas promoções, transferências de atividades e admissões de pessoal;

- Reciclar na política de qualidade da empresa e conscientizar nas novas metodologias implantadas.

O treinamento como qualquer outra atividade empresarial, deve ser sempre planejado e seus programas devem ser coordenados por órgãos gerenciais em todos os níveis.

O planejamento do programa de treinamento permitirá: coordenação dos planos de todos os departamentos, maior efetivação no uso dos tempos, combinação econômica dos homens, máquinas, equipamentos e métodos de trabalho de cada área de trabalho; estabelecimento correto da ação a ser seguida e do objetivo que se quer alcançar; execução realista e prática; determinação racial do que deve ser feito, quando, onde e como; sequência de fases do trabalho para que resulte em economia de tempo, de esforços e em maior rendimento (FONTES, I980, p. 3I).

Caldwell (I988) relata sobre os benefícios do treinamento tanto para os funcionários como para as organizações.

Funcionários:

- Maior satisfação no trabalho: o funcionário tem prazer em realizar o seu trabalho quando sabe fazê-lo corretamente;

- Aceitação dos colegas: o funcionário capacitado não depende dos demais, e isso faz com que ele seja aceito com mais facilidade pela equipe;

- Maior autoestima: a combinação da satisfação com o trabalho e a aceitação dos colegas leva o indivíduo ter maior autoestima;

- Oportunidade de prosseguir na organização: quando o funcionário exerce suas atividades com excelência, aumentam as suas responsabilidades dentro da organização; 
- Potencial para ganhar mais: com tudo isso o funcionário pode aumentar o seu nível salarial.

Organização:

- Maior produtividade: funcionários que sabem executar o seu trabalho adequadamente são mais eficazes e produtivos;

- Maior satisfação dos clientes: os funcionários atendem os clientes adequadamente e conseguem resolver os problemas com sucesso;

- Melhor qualidade: os funcionários passam a priorizar a qualidade.

Para Marras (2000) existem três objetivos considerados mais importantes da área de treinamento. São eles:

- Formação profissional: tem como meta alcançar um grau ideal de capacidade laboral para determinada profissão, repassando todos os conhecimentos e práticas necessárias para o bom desempenho de uma função.

- Especialização: oferece ao treinando um campo de conhecimento ou prática específica dentro de uma área de trabalho para a otimização dos resultados.

- Reciclagem: tem como finalidade básica rever conceitos, conhecimentos ou práticas de trabalho, renovando-os ou atualizando-os de acordo com as necessidades.

\section{Processo dos Programas de Treinamento}

O processo dos programas de treinamento e desenvolvimento segundo Marras (2000) segue basicamente o fluxo descrito abaixo, dividindo o processo em quatro etapas: Diagnóstico, Programação, Execução e Avaliação. Abaixo explica-se melhor cada um deles:

Diagnóstico: nesta etapa é realizado o levantamento e a análise que dão subsídio ao plano de treinamento. É definido também quem será treinado e o que deverá ser aprendido no treinamento.

Programação: cabe a esta fase, organizar as prioridades entre o necessário e o possível, enfocando os recursos disponíveis e as necessidades gerais. Essa etapa do processo de treinamento consiste em analisar e coordenar as ações consideradas 
prioritárias e necessárias para serem implementadas em módulos de aprendizagem, conforme previamente planejado.

Execução: é a aplicação daquilo que foi planejado e programado para suprir as necessidades de aprendizagem detectadas na organização.

Nesta fase pode ser aplicado vários recursos que facilitam o entendimento e oferecem opções de assimilação diferenciadas para os treinados. Abaixo estão algumas técnicas:

- Aula expositiva: o instrutor repassa oralmente a um grupo de treinados os conhecimentos necessários.

- Estudo de caso: pede-se ao treinando para analisar por escrito uma case apresentado pelo instrutor, e após a análise cuidadosa, ele deverá apresentar alternativas de solução.

- Dramatização: o treinando assume um determinado "papel”, previamente dado pelo instrutor e assim, realiza uma dramatização trabalhando os ângulos emocionais e racionais do treinando.

- Workshop: técnica que reúne treinandos para explorar soluções grupais de problemas práticos do dia-a-dia. Estimula a criatividade e a participação, promovendo o comprometimento conjunto de decisões.

- Brainstorming (tempestade de ideias): técnica utilizada para provocar principalmente a criatividade e a rapidez de raciocínio dos participantes. O instrutor é quem indica um assunto e os treinandos de pronto expressam seu ponto de vista ou aquilo que pensam a respeito do assunto em pauta.

- Simulação: instrumento muito utilizado para treinamento de operações técnicas, como máquinas e equipamentos, onde pode-se aferir a habilidade motora e/ou visual dos treinandos e suas reações imediatas a certas propostas.

- Painel: técnica que utiliza a apresentação de discussão conjunta de especialistas em determinados assuntos para a plateia de ouvintes, neste caso, os treinandos.

- Simpósio: é uma técnica que segue o mesmo formato do painel, com a diferença que se apresenta de maneira mais formal. Os expositores apresentam-se individualmente, cada um apresentando uma faceta do tema central. 
- Palestra: essa técnica é utilizada quando se deseja apresentar aos treinandos a opinião ou o conhecimento de uma pessoa em especial.

- Conferência: segue o mesmo formato da palestra, diferenciando-se daquela pela maior formalidade com que é realizada a apresentação.

Avaliação: esta é a última etapa do processo de treinamento, que tem por finalidade aferir os resultados conseguidos comparativamente àquilo que foi planejado $\mathrm{e}$ esperado pela organização. Muitas vezes a organização acredita que não se pode avaliar com exatidão os resultados obtidos pelo treinamento. Todavia, o bom planejamento $\mathrm{e}$ avaliação do processo levarão a um retorno eficaz do procedimento.

Franco e Corrêa (2OII) apresentam vários métodos para avaliar a extensão em que os programas de treinamento aprimoram o aprendizado, afetam o comportamento no trabalho e influem no resultado financeiro de uma organização.

Segundo os autores, existem quatro critérios básicos de avaliar o treinamento: reações dos treinandos; aprendizado efetivado; comportamento dos treinandos e resultados alcançados. Abaixo se explica o exposto.

Critério das Reações: Consiste na avaliação das reações de cada participante do treinamento. Alcançando a satisfação dos treinandos, fica mais fácil de chegar ao objetivo da empresa. Através deste critério a organização também pode obter um feeback, sugestões e críticas sobre o treinamento. Esse critério é aplicado no término do treinamento, podendo ser feito através de questionários ou presencial. Contudo, os avaliadores devem estar atentos aos depoimentos e conclusões dos treinamentos, pois em muitos casos opiniões brilhantes não mostram uma realidade específica do que se deseja avaliar, por isso, a avaliação deve ser feita mais aprofundada.

Critério de Aprendizado: Tem o objetivo de apurar a efetivação da aprendizagem. Para uma apuração mais concreta e real recomenda-se a aplicação em dois momentos: antes e depois do treinamento, assim será possível realizar comparações do tipo "como era e como está”.

A empresa também pode escolher pela técnica "grupo-controle" e "grupo de treinandos”. O primeiro grupo é formado de pessoas da organização que não foram inclusas no programa de treinamento, mas que apresentam as mesmas características dos 
treinandos. A avaliação consiste em comparar a mudança ocorrida no comportamento dos funcionários que receberam o treinamento face aos funcionários do grupo-controle.

Critério de Comportamento: A organização deve ter em mente que em muitas situações o treinamento precisa modificar o comportamento dos funcionários. Para que isso ocorra, algumas abordagens devem ser adotadas durante este programa, como, a aproximação máxima das situações que ocorrem no dia a dia da empresa. A organização deve facilitar e apoiar este novo comportamento não ocasionando constrangimento para o colaborador e trabalhar também com a autoconfiança do colaborador.

Critério de Resultados: Consiste no acompanhamento do treinando ao longo de um período de tempo, visando observar mudanças ocorridas em seu comportamento. Porém outro ponto determinante que ocorre neste critério está no fato de que as organizações interessadas no seu retorno financeiro oferecem treinamentos sofisticados aos seus colaboradores, pois como o objetivo maior deste critério é cobrar os resultados, a meta da empresa deve ser então alcançada como aumento da produção, redução de custos, lucro, desperdícios entre outros.

\section{Competências: Conceitos e Tipologias}

O dicionário inglês Webster (I98I) define "competência” como "qualidade ou estado de ser funcionalmente adequado ou de ter suficiente conhecimento, julgamento, habilidade ou força para determinada tarefa (the quality or state of being functionally adequate or having suficiente skill or strenght for a particular duty)". Tal definição aponta dois pontos ligados à competência: conhecimento e tarefa.

O dicionário da língua portuguesa Aurélio (1975) define alguns aspectos semelhantes: capacidade de resolver qualquer assunto, aptidão, idoneidade - e introduz capacidade legal para julgar pleito.

Segundo Dutra (200I) existem diferentes elementos que podem definir a competência. De um lado tem-se a organização, com um conjunto próprio de competências. Estas se originam da gênese e do processo de desenvolvimento da organização e são concretizadas no seu patrimônio de conhecimentos. Tal patrimônio, por sua vez, estabelece as vantagens competitivas da empresa no contexto em que está inserido. 
De outro lado têm-se as pessoas, com seu conjunto de competências que pode ou não estar sendo aproveitado pela empresa.

McClelland (I990) afirma que competência é uma característica subjacente a uma pessoa casualmente relacionada com um desempenho superior na realização de uma tarefa ou determinada situação. $\mathrm{O}$ autor diferencia competência de aptidões ou talento natural da pessoa e complementa o conceito como conjunto de habilidades, demonstração de um talento natural na prática; de conhecimentos, o que as pessoas precisam saber para desempenhar uma tarefa; e atitudes.

Segundo Zarifian (I999) competência é a inteligência prática de situações que se apoia nos conhecimentos adquiridos e os transforma com tanto mais força quanto maior for a complexidade das situações.

Ainda nas ideias de Zarifian (I999) o conceito de competência procura ir além do conceito de qualificação, usualmente definida pelos requisitos associados à posição ou ao cargo, ou pelos saberes ou estoque de conhecimentos da pessoa, os quais são classificados e certificados pelo sistema educacional. O conceito de competência referese à capacidade da pessoa assumir iniciativas, ir além das atividades prescritas, ser capaz de compreender e dominar novas situações no trabalho, ser responsável e reconhecida por isso.

A competência do indivíduo não é um estado, não se reduz a um conhecimento ou know-how específico. Le Boterf (I995) define competência como o entrecruzamento de três eixos, formados pela pessoa (sua biografia, socialização), sua formação educacional e por sua experiência profissional.

Le Boterf (I995) ainda define competências como saber agir, mobilizar recursos, integrar saberes múltiplos e complexos, saber aprender, saber se engajar, assumir responsabilidades e ter visão estratégica.

Dutra (20OI) afirma que as pessoas possuem um determinado conjunto de conhecimentos, habilidades e atitudes, o que não garante que a organização se beneficiará diretamente.

Organização e pessoas, lado a lado, propiciam um processo contínuo de troca de competências. A empresa transfere seu patrimônio para as pessoas, enriquecendoas e preparando-as para enfrentar novas situações profissionais e pessoais, dentro ou fora da organização. As pessoas, por seu turno, ao desenvolver sua capacidade 
individual, transferem para a organização seu aprendizado, dando-lhe condições para enfrentar novos desafios (DUTRA, 200I, p. 27).

Assim, o autor apresenta uma noção extremamente importante a ser incorporada ao conceito de competência que é a entrega. O termo "entrega" refere-se ao indivíduo saber agir de maneira responsável e ser reconhecido por isso.

Fleury (2002) define que competência não se limita ao estoque de conhecimentos teóricos e empíricos do indivíduo nem se encontra encapsulada na tarefa.

A autora ainda define que a competência deve agregar valor econômico para a organização e valor social para o indivíduo.

No Quadro I seguem as definições de cada autor sobre o conceito de competências.

Quadro I - Definições de competência na visão de diversos autores

\begin{tabular}{|c|c|c|c|c|}
\hline ANO & AUTOR & ORIGEM & CONCEITO & INTERPRETAÇÃO \\
\hline 1973 & McClelland & Estados Unidos & $\begin{array}{c}\text { Alta Performance } \\
\text { CHA }\end{array}$ & $\begin{array}{l}\text { Competência é o conjunto de } \\
\text { conhecimentos, habilidades e atitudes } \\
\text { que um indivíduo detém para realizar as } \\
\text { tarefas prescritas de um cargo. }\end{array}$ \\
\hline 1995 & Le Boterf & França & $\begin{array}{l}\text { Encruzilhada: } \\
\text { Pessoa, } \\
\text { Formação Profissional e } \\
\text { Experiência Profissional }\end{array}$ & $\begin{array}{c}\text { Competência como o entrecruzamento } \\
\text { de três eixos: formação pessoal } \\
\text { (biografia e socialização do indivíduo), } \\
\text { formação educacional e experiência } \\
\text { profissional. }\end{array}$ \\
\hline 1999 & Zarifian & França & Inteligência Prática & $\begin{array}{l}\text { Competência é a inteligência prática de } \\
\text { situações que se apoia nos } \\
\text { conhecimentos adquiridos e os } \\
\text { transforma com tanto mais força quanto } \\
\text { maior for a complexidade das situações. }\end{array}$ \\
\hline 2000 & Fleury & Brasil & $\begin{array}{r}\text { Saber Agir Responsável; } \\
\text { Não se limita ao estoque } \\
\text { de conhecimento; } \\
\text { Agrega valor econômico } \\
\text { à organização e } \\
\text { Agrega valor social ao } \\
\text { indivíduo }\end{array}$ & $\begin{array}{c}\text { Competência significa saber agir, } \\
\text { mobilizar recursos, integrar saberes } \\
\text { múltiplos e complexos, saber aprender, } \\
\text { saber se engajar, assumir } \\
\text { responsabilidades e ter visão } \\
\text { estratégica para agregar valor } \\
\text { econômico à organização e valor social } \\
\text { ao indivíduo. }\end{array}$ \\
\hline 2001 & Dutra & Brasil & Entrega & $\begin{array}{l}\text { Capacidade de uma pessoa gerar } \\
\text { resultados de acordo com os objetivos } \\
\text { organizacionais, isto é, pelos resultados } \\
\text { e desempenho obtidos através do } \\
\text { conjunto de qualidades que lhe é } \\
\text { inerente. }\end{array}$ \\
\hline
\end{tabular}


Segundo Mascarenhas (2008) existem três tipos de competências:

- Competências Organizacionais: São as competências necessárias para que a organização e as equipes de trabalho realizem seus objetivos;

- Competências Profissionais: São as competências necessárias para o exercício de cada cargo, função ou profissão;

- Competências Individuais: São as competências que os funcionários detêm.

Ainda na visão do autor acima, as competências são dividas em dois grupos:

Técnicas e Comportamentais. As técnicas se referem ao cargo e as comportamentais ao indivíduo como pessoa.

A equipe de pesquisa salarial da Catho Online (20I2) afirma que competência técnica é aquela que é obtida através de educação formal, treinamentos e experiência profissional, já a competência comportamental é aquela que possibilita maior probabilidade de obtenção de sucesso na execução de determinadas atividades, podem ser inerentes às características de personalidade de um indivíduo, ou obtidas no convívio social, podem ser obtidas e aprimoradas através de treinamentos.

Abaixo segue a Figura I, com exemplos dos grupos de competências e a base da competência que seria o CHA, no qual conhecimento (é saber), as habilidades (saber fazer) e por fim, as atitudes (querer fazer).

Figura I - Competências Técnicas e Comportamentais e o CHA

\begin{tabular}{|c|c|c|}
\hline \multicolumn{2}{|c|}{ Técnicas } & Comportamentais \\
\hline Conhecimento & Habilidade & Atitude \\
\hline SABER TÉCNICA & SABER FAZER & QUERER FAZER \\
\hline $\begin{array}{r}\mathrm{Ic} \\
\mathrm{N} \\
\mathrm{T} \\
\text { Infc } \\
\text { Fer } \\
\text { Cálculos }\end{array}$ & $\begin{array}{l}\text { as } \\
\text { as } \\
\text { cas } \\
\text { itica } \\
\text { ntas } \\
\text { temáticos }\end{array}$ & $\begin{array}{c}\text { Iniciativa } \\
\text { Criatividade } \\
\text { Flexibilidade } \\
\text { Comunicação } \\
\text { Foco no Cliente } \\
\text { Foco em Resultado }\end{array}$ \\
\hline
\end{tabular}

Fonte: Leme (2007) 


\section{Metodologia de Pesquisa}

Método é o conjunto das atividades sistemáticas e racionais que, com maior segurança e economia, permite alcançar o objetivo - conhecimentos válidos e verdadeiros -, traçando o caminho a ser seguido, detectando erros e auxiliando as decisões do cientista (LAKATOS e MARCONI, I99I, p.83).

Este item apresenta como a pesquisa foi realizada, definindo qual foi a base teórica e o tipo de pesquisa utilizada, bem como a amostra de pesquisa, além das técnicas tanto de coleta quanto de análise de dados.

\section{Tipologia de Pesquisa}

O tipo de pesquisa utilizada foi exploratória, que segundo Roesch (I996, p.64) "propõe-se levantar, definir problemas e explorar o ambiente".

Ainda nas ideias de Roesch (1996, p. 68), a pesquisa exploratória tem o propósito de "apresentar propostas de planos ou sistemas para solucionar problemas organizacionais".

A pesquisa exploratória possibilita que teorias ou conceitos existentes possam ser aplicados a um determinado problema, desta forma, o presente estudo identificou problemas enfrentados no I ${ }^{\circ}$ Registro de Imóveis e Anexos de Piracicaba e propôs recomendações estratégicas através de conceitos teóricos.

A pesquisa enquadra-se também em uma pesquisa aplicada, pois “caracteriza-se por seu interesse prático, isto é, que os resultados sejam aplicados ou utilizados, imediatamente, na solução de problemas que ocorrem na realidade" (MARCONI e LAKATOS, 2002, p. 20).

\section{Amostra da Pesquisa}

“A amostra é uma parcela convenientemente selecionada do universo (população); é um subconjunto do universo”. (MARCONI e LAKATOS, 2002 p.3O).

O conjunto de pessoas ou empresas que formam o alvo da pesquisa é chamado de universo da pesquisa. Assim, a amostra da pesquisa compreendeu 27 colaboradores, e a pesquisa também é composta pelo estudo de caso do I ${ }^{\circ}$ Registro de Imóveis, Títulos e Documentos e Civil de Pessoa Jurídica de Piracicaba. 


\section{Instrumento e Técnica de Coleta de Dados}

Os dados na pesquisa foram coletados por meio de dados secundários. utilizouse de dados da organização, tais como: documentos oficiais, tabelas e registros. Aplicouse da entrevista para coletar os dados sobre a avaliação dos treinamentos e o mapeamento de competências.

Para complementar a coleta de dados, usou-se da técnica observação da pesquisadora.

A observação é uma técnica de coleta de dados para conseguir informações e utiliza na obtenção de determinados aspectos de realidade. Não consiste apenas em ver e ouvir, mas também em examinar fatos ou fenômenos que se deseja estudar (MARCONI E LAKATOS, 2002, p. 88).

\section{Técnicas de Análise de Dados}

Os dados coletados na pesquisa foram analisados num primeiro momento por meio quantitativo (quadros e frequências) e num segundo momento utilizou-se da análise qualitativa, que segundo Roesch (I996 p. I46) "é apropriada para avaliação formativa, quando se trata de melhorar a efetividade de um programa ou plano, ou mesmo quando é o caso da proposição de planos”.

\section{Resultados da Pesquisa - Avaliação dos programas de treinamento e desenvolvimento e mapeamento das competências}

Avaliar é a última etapa do processo de treinamento, que deve aferir os resultados do que foi planejado e esperado pela organização.

Cada colaborador ao participar do treinamento deve responder ao questionário avaliando os treinamentos que participou, para que assim a organização possa cada vez mais melhorar os treinamentos oferecidos.

Dessa forma, para a realização deste estudo, foi aplicado no $\mathrm{I}^{\circ}$ Registro de Imóveis e Anexos de Piracicaba um questionário de avaliação referente aos dois programas de treinamento e desenvolvimento implantados pela instituição intitulados como Normas da Corregedoria e Prática no Direito Registral Imobiliário. 
Diante dos colaboradores pesquisados, o Quadro 2 apresenta quais são as suas funções. Pode-se notar que estão bem distribuídas as funções, pois 51,85\% são escreventes e 48,I5\% são auxiliares.

Quadro 2 - Funções

\begin{tabular}{|c|c|c|}
\hline 1- Cargo/ Função & F & \% \\
\hline Escrevente & 14 & 51,85 \\
\hline Auxiliar & 13 & 48,15 \\
\hline Total & $\mathbf{2 7}$ & $\mathbf{1 0 0}$ \\
\hline
\end{tabular}

Fonte: Elaborado pela autora

Referente à idade dos colaboradores pesquisados, verifica-se no Quando 3 que mais da metade, ou seja 5I,85\% dos colaboradores compõe o intervalo entre I8 a 28 anos. Apenas 3,70\% compreende a última faixa analisada que é de 59 a 68 anos de idade.

\section{Quadro3-Idade}

\begin{tabular}{|c|c|c|}
\hline 2- Idade & F & \% \\
\hline 18 a 28 & 14 & 51,85 \\
\hline 29 a 38 & 8 & 29,63 \\
\hline 39 a 48 & 2 & 7,41 \\
\hline 49 a 58 & 2 & 7,41 \\
\hline 59 a 68 & 1 & 3,70 \\
\hline Total & $\mathbf{2 7}$ & 100 \\
\hline
\end{tabular}

Fonte: Elaborado pela autora

Referente ao sexo dos colaboradores pesquisados, verifica-se no Quadro 4 que a maioria são mulheres compreendendo $66,67 \%$ do total e $33,33 \%$ são homens.

Quadro 4-Sexo

\begin{tabular}{|c|c|c|}
\hline 3- Sexo & F & \% \\
\hline Feminino & 18 & 66,67 \\
\hline Masculino & 9 & 33,33 \\
\hline Total & $\mathbf{2 7}$ & $\mathbf{1 0 0}$ \\
\hline
\end{tabular}

Fonte: Elaborado pela autora

Diante dos colaboradores pesquisados, o Quadro 5 apresenta quanto tempo cada colaborador trabalha no cartório. Pode-se notar que a maioria esta na faixa de o a 5 anos, 
pois 74,08\% dos colaboradores compreendem esse nível. Apenas $3,70 \%$ trabalham entre I8 a 23 anos e também 3,70\% trabalham há mais de 24 anos no local do estudo.

Quadro5-Tempo de trabalho no cartório

\begin{tabular}{|c|c|c|}
\hline $\begin{array}{c}\text { 4- Quanto tempo trabalha no } \\
\text { cartório? }\end{array}$ & F & \% \\
\hline 0 a 5 anos & 20 & 74,08 \\
\hline 6 a 11 anos & 3 & 11,11 \\
\hline 12 a 17 anos & 2 & 7,41 \\
\hline 18 a 23 anos & 1 & 3,70 \\
\hline mais de 24 anos & 1 & 3,70 \\
\hline Total & $\mathbf{2 7}$ & $\mathbf{1 0 0}$ \\
\hline
\end{tabular}

Fonte: Elaborado pela autora

Referente ao estado civil dos colaboradores pesquisados verifica-se no Quando 6 que mais da metade, ou seja $55,56 \%$ dos colaboradores são solteiros. Compreendem 40,74\% os colaboradores casados e apenas 3,70\% são viúvos.

Quadro6-Estado Civil

\begin{tabular}{|c|c|c|}
\hline $\begin{array}{c}\text { 5- Qual é seu estado } \\
\text { civil? }\end{array}$ & F & $\%$ \\
\hline Solteiro & 15 & 55,56 \\
\hline Casado & 11 & 40,74 \\
\hline Separado & 1 & 3,70 \\
\hline Viúvo & 0 & 0 \\
\hline Total & $\mathbf{2 7}$ & $\mathbf{1 0 0}$ \\
\hline
\end{tabular}

Fonte: Elaborado pela autora

Diante dos colaboradores pesquisados, o Quadro 7 apresenta se os colaboradores atualmente estudam. Pode-se notar que a maioria não estuda, totalizando 85,I9\%. Apenas I4,81\% ainda estudam.

Quadro 7 - Estudante atualmente?

\begin{tabular}{|c|c|c|}
\hline 6 - Estuda Atualmente? & $\mathbf{F}$ & $\mathbf{\%}$ \\
\hline Sim & 4 & 14,81 \\
\hline Não & 23 & 85,19 \\
\hline Total & $\mathbf{2 7}$ & $\mathbf{1 0 0}$ \\
\hline
\end{tabular}

Fonte: Elaborado pela autora 
Diante dos pesquisados, o Quadro 8 apresenta a escolaridade dos colaboradores. Pode-se notar que a maioria possui o ensino superior completo, totalizando $40,74 \%$. Apenas 3,70\% possuem o ensino fundamental completo.

Quadro 8-Escolaridade

\begin{tabular}{|c|c|c|}
\hline 7- Qual é sua escolaridade? & F & \% \\
\hline Ensino fundamental completo & 1 & 3,70 \\
\hline Ensino fundamental incompleto & 0 & 0 \\
\hline Ensino médio completo & 10 & 37,04 \\
\hline Ensino médio incompleto & 0 & 0 \\
\hline Ensino superior completo & 11 & 40,74 \\
\hline Ensino superior incompleto & 3 & 11,11 \\
\hline Outros & 2 & 7,41 \\
\hline Total & $\mathbf{2 7}$ & 100 \\
\hline
\end{tabular}

Fonte: Elaborado pela autora

Diante dos colaboradores pesquisados, o Quadro 9 apresenta qual foi o número de horas destinado pelo cartório em treinamentos. Pode-se verificar que a maioria dos colaboradores teve entre II a I5 horas de treinamento anual, compreendendo 33,33\% do total de pesquisados. Apenas $3,70 \%$ tiveram de 6 a Io horas de treinamento.

Quadro 9- Número de horas destinado pelo cartório em treinamento

\begin{tabular}{|c|c|c|}
\hline $\begin{array}{c}\text { 8- No ano corrente, qual o número de horas } \\
\text { Ihe foi destinado pelo cartório em } \\
\text { treinamentos? }\end{array}$ \\
\hline F & $\%$ \\
\hline menos de 5 horas & 0 & 0 \\
\hline de 6 a 10 horas & 1 & 3,70 \\
\hline de 11 a 15 horas & 9 & 33,33 \\
\hline de 16 a 20 horas & 5 & 18,52 \\
\hline de 21 a 25 horas & 7 & 25,93 \\
\hline acima de 26 horas & 5 & 18,52 \\
\hline Total & $\mathbf{2 7}$ & 100 \\
\hline
\end{tabular}

Fonte: Elaborado pela autora

O Quadro Io apresenta qual foi o envolvimento do oficial do cartório nas práticas de treinamento. Pode-se notar que mais da metade dos colaboradores, ou seja, um total de $62,96 \%$ afirmam que frequentemente o oficial se envolve nas práticas do treinamento. Apenas II,II\% afirmam que raramente há o envolvimento do oficial e nenhum afirmou que nunca houve o envolvimento. 
Quadro Io-Envolvimento do oficial do cartório nas práticas de treinamento.

\begin{tabular}{|c|c|c|}
\hline \multicolumn{3}{|c|}{$\begin{array}{c}\text { 9- O envolvimento do oficial do cartório nas } \\
\text { práticas de treinamento geralmente é: }\end{array}$} \\
\hline \multicolumn{2}{|c|}{ F } & $\%$ \\
\hline Frequente & 17 & 62,96 \\
\hline Ocasional & 7 & 25,93 \\
\hline Raramente & 3 & 11,11 \\
\hline Nunca & 0 & 0 \\
\hline Total & $\mathbf{2 7}$ & $\mathbf{1 0 0}$ \\
\hline
\end{tabular}

Fonte: Elaborado pela autora

Diante dos colaboradores pesquisados, o Quadro II apresenta com qual frequência devem ser realizados os treinamentos no cartório. 37,04\% dos colaboradores acreditam que os treinamentos devem ser realizados regularmente, já 29,63\% afirmam que os treinamentos devem ser realizados frequentemente e nenhum acredita que os treinamentos não devem ser realizados.

Quadro II - A frequência que deve ser realizado os treinamentos

\begin{tabular}{|c|c|c|}
\hline \multicolumn{3}{|c|}{$\begin{array}{c}\text { 10- Na sua opinião, com qual frequência } \\
\text { deve ser realizado os treinamentos? }\end{array}$} \\
\hline F & 9 & $\%$ \\
\hline Sempre & 8 & 29,33 \\
\hline Frequentemente & 10 & 37,04 \\
\hline Regularmente & 0 & 0 \\
\hline Não deve ser realizado & $\mathbf{2 7}$ & $\mathbf{1 0 0}$ \\
\hline Total &
\end{tabular}

Fonte: Elaborado pela autora

Diante dos colaboradores pesquisados, o Quadro I2 apresenta a opinião dos colaboradores em relação aos aspectos que compõe o treinamento. Com 96,30\% o componente "organização" foi apontado como o mais adequado, já o componente "recursos audiovisuais" foi apontado como o mais inadequado, com $62,96 \%$. 
Quadro I2 - A frequência que deve ser realizado os treinamentos

\begin{tabular}{|c|c|c|c|c|c|c|}
\hline \multicolumn{7}{|c|}{ 11- Em relação aos aspectos que compõe o treinamento dê sua opinião: } \\
\hline \multirow{2}{*}{ Componentes do treinamento } & \multicolumn{2}{|c|}{ Adequados } & \multicolumn{2}{|c|}{ Inadequados } & \multirow{2}{*}{ Total F } & \multirow{2}{*}{ Total \% } \\
\hline & $\mathbf{F}$ & $\%$ & $\mathbf{F}$ & $\%$ & & \\
\hline Recursos visuais & 14 & 51,85 & 13 & 48,15 & 27 & 100 \\
\hline Recursos Auditivos & 21 & 77,78 & 6 & 22,22 & 27 & 100 \\
\hline Materiais & 19 & 70,37 & 8 & 29,63 & 27 & 100 \\
\hline Recursos Audiovisuais & 10 & 37,04 & 17 & 62,96 & 27 & 100 \\
\hline Sala de aula & 16 & 59,26 & 11 & 40,74 & 27 & 100 \\
\hline Organização & 26 & 96,30 & 1 & 3,70 & 27 & 100 \\
\hline Assuntos & 23 & 85,19 & 4 & 14,81 & 27 & 100 \\
\hline Duração do programa de treinamento & 21 & 77,78 & 6 & 22,22 & 27 & 100 \\
\hline
\end{tabular}

Fonte: Elaborado pela autora

Diante dos colaboradores pesquisados e considerando os dois programas de treinamentos aplicados: Normas da Corregedoria e Prática no Direito Registral Imobiliário, o Quadro I3, apresenta a opinião dos colaboradores em relação às principais melhorias que o treinamento trouxe para cada um deles.

Observa-se que com o treinamento sobre as Normas da Corregedoria as melhorias mais apontadas foram "ajuda a acompanhar as mudanças do cartório" e também a "aquisição de conhecimentos" com a porcentagem de 7O,37\%. Já a melhoria menos assinalada foi "redução de custos" com apenas 3,70\%.

Referindo se ao treinamento sobre a Prática no Direito Registral Imobiliário, pode-se observar que a melhoria mais apontada com 74,07\% foi a "aquisição de conhecimentos", em contrapartida as melhorias "clima organizacional” e também a melhoria "redução de custos" apontaram o menor índice com apenas $3,70 \%$.

Nota-se de uma maneira geral que as melhorias com as porcentagens mais elevadas foram as quais se referem às competências técnicas, já as melhorias relacionadas às competências comportamentais foram as quais apresentaram os menores índices. 
Quadro 13 - Melhorias que os colaboradores obtiveram com os programas de treinamentos aplicados

\begin{tabular}{|c|c|c|c|c|c|c|c|c|}
\hline \multicolumn{9}{|c|}{ 12- Quais as melhorias que você obteve em relação aos programas de treinamentos, abaixo descritos e que você participou: } \\
\hline \multirow[b]{2}{*}{ Principais Melhorias } & \multicolumn{8}{|c|}{ N. Corregedoria } \\
\hline & $\begin{array}{c}\text { Houve } \\
\text { melhoria }\end{array}$ & $\%$ & Não Houve Melhoria & $\%$ & $\begin{array}{c}\text { Não } \\
\text { Participou }\end{array}$ & $\%$ & $\mathbf{F}$ & $\%$ \\
\hline Ajuda a acompanhar as mudanças do cartório & 19 & 70,37 & 2 & 7,41 & 6 & 22,22 & 27 & 100 \\
\hline Aperfeiçoamento das atividades & 18 & 66,67 & 3 & 11,11 & 6 & 22,22 & 27 & 100 \\
\hline Aquisição de conhecimentos & 19 & 70,37 & 2 & 7,41 & 6 & 22,22 & 27 & 100 \\
\hline Atendimento ao cliente & 8 & 29,63 & 13 & 48,15 & 6 & 22,22 & 27 & 100 \\
\hline $\begin{array}{l}\text { Aumento da aprendizagem como o conhecimento e } \\
\text { habilidades }\end{array}$ & 18 & 66,67 & 3 & 11,11 & 6 & 22,22 & 27 & 100 \\
\hline Aumento da produtividade & 9 & 33,33 & 12 & 44,44 & 6 & 22,22 & 27 & 100 \\
\hline Clima organizacional & 5 & 18,52 & 16 & 59,26 & 6 & 22,22 & 27 & 100 \\
\hline Competência pessoal/Qualificação profissional & 17 & 62,96 & 4 & 14,81 & 6 & 22,22 & 27 & 100 \\
\hline Imagem da empresa & 7 & 25,93 & 14 & 51,85 & 6 & 22,22 & 27 & 100 \\
\hline Maior agilidade no trabalho & 9 & 33,33 & 12 & 44,44 & 6 & 22,22 & 27 & 100 \\
\hline Maior competitividade & 2 & 7,41 & 19 & 70,37 & 6 & 22,22 & 27 & 100 \\
\hline Maior flexibilidade & 3 & 11,11 & 18 & 66,67 & 6 & 22,22 & 27 & 100 \\
\hline Mantém a pessoa informada e atualizada & 16 & 59,26 & 5 & 18,52 & 6 & 22,22 & 27 & 100 \\
\hline Melhor qualidade de vida no trabalho - QVT & 4 & 14,81 & 17 & 62,96 & 6 & 22,22 & 27 & 100 \\
\hline Melhor realização das tarefas & 15 & 55,56 & 6 & 22,22 & 6 & 22,22 & 27 & 100 \\
\hline Melhoria na comunicação & 13 & 48,15 & 8 & 29,63 & 6 & 22,22 & 27 & 100 \\
\hline Mudanças e inovações & 11 & 40,74 & 10 & 37,04 & 6 & 22,22 & 27 & 100 \\
\hline Possibilita aumento de salário & 7 & 25,93 & 14 & 51,85 & 6 & 22,22 & 27 & 100 \\
\hline Redução de acidentes de trabalho & 0 & 0,00 & 21 & 77,78 & 6 & 22,22 & 27 & 100 \\
\hline Redução de custos & 1 & 3,70 & 20 & 74,07 & 6 & 22,22 & 27 & 100 \\
\hline Redução de erros e desperdicios & 12 & 44,44 & 9 & 33,33 & 6 & 22,22 & 27 & 100 \\
\hline Relacionamento entre cartório e funcionário & 11 & 40,74 & 10 & 37,04 & 6 & 22,22 & 27 & 100 \\
\hline Relações pessoais no trabalho & 9 & 33,33 & 12 & 44,44 & 6 & 22,22 & 27 & 100 \\
\hline Retorno sobre o investimento & 5 & 18,52 & 16 & 59,26 & 6 & 22,22 & 27 & 100 \\
\hline Relacionamento na equipe & 8 & 29,63 & 13 & 48,15 & 6 & 22,22 & 27 & 100 \\
\hline Foco em resultados & 11 & 40,74 & 10 & 37,04 & 6 & 22,22 & 27 & 100 \\
\hline Comunicação na organização & 6 & 22,22 & 15 & 55,56 & 6 & 22,22 & 27 & 100 \\
\hline & \multicolumn{8}{|c|}{ Prática no Direito Imobiliáro } \\
\hline Principais Melhorias & $\begin{array}{l}\text { Houve } \\
\text { melhoria }\end{array}$ & $\%$ & Não Houve Melhoria & $\%$ & $\begin{array}{c}\text { Não } \\
\text { Participou }\end{array}$ & $\%$ & $\mathbf{F}$ & $\%$ \\
\hline Ajuda a acompanhar as mudanças do cartório & 17 & 62,96 & 5 & 18,52 & 5 & 18,52 & 27 & 100 \\
\hline Aperfeiçoamento das atividades & 15 & 55,56 & 7 & 25,93 & 5 & 18,52 & 27 & 100 \\
\hline Aquisição de conhecimentos & 20 & 74,07 & 2 & 7,41 & 5 & 18,52 & 27 & 100 \\
\hline Atendimento ao cliente & 5 & 18,52 & 17 & 62,96 & 5 & 18,52 & 27 & 100 \\
\hline $\begin{array}{l}\text { Aumento da aprendizagem como o conhecimento e } \\
\text { habilidades }\end{array}$ & 19 & 70,37 & 3 & 11,11 & 5 & 18,52 & 27 & 100 \\
\hline Aumento da produtividade & 11 & 40,74 & 11 & 40,74 & 5 & 18,52 & 27 & 100 \\
\hline Clima organizacional & 1 & 3,70 & 21 & 77,78 & 5 & 18,52 & 27 & 100 \\
\hline Competência pessoal/Qualificação profissional & 16 & 59,26 & 6 & 22,22 & 5 & 18,52 & 27 & 100 \\
\hline Imagem da empresa & 3 & 11,11 & 19 & 70,37 & 5 & 18,52 & 27 & 100 \\
\hline Maior agilidade no trabalho & 9 & 33,33 & 13 & 48,15 & 5 & 18,52 & 27 & 100 \\
\hline Maior competitividade & 3 & 11,11 & 19 & 70,37 & 5 & 18,52 & 27 & 100 \\
\hline Maior flexibilidade & 3 & 11,11 & 19 & 70,37 & 5 & 18,52 & 27 & 100 \\
\hline Mantém a pessoa informada e atualizada & 16 & 59,26 & 6 & 22,22 & 5 & 18,52 & 27 & 100 \\
\hline Melhor qualidade de vida no trabalho - QVT & 2 & 7,41 & 20 & 74,07 & 5 & 18,52 & 27 & 100 \\
\hline Melhor realização das tarefas & 16 & 59,26 & 6 & 22,22 & 5 & 18,52 & 27 & 100 \\
\hline Melhoria na comunicação & 10 & 37,04 & 12 & 44,44 & 5 & 18,52 & 27 & 100 \\
\hline Mudanças e inovações & 11 & 40,74 & 11 & 40,74 & 5 & 18,52 & 27 & 100 \\
\hline Possibilita aumento de salário & 7 & 25,93 & 15 & 55,56 & 5 & 18,52 & 27 & 100 \\
\hline Redução de acidentes de trabalho & 0 & 0,00 & 22 & 81,48 & 5 & 18,52 & 27 & 100 \\
\hline Redução de custos & 1 & 3,70 & 21 & 77,78 & 5 & 18,52 & 27 & 100 \\
\hline Redução de erros e desperdicios & 12 & 44,44 & 10 & 37,04 & 5 & 18,52 & 27 & 100 \\
\hline Relacionamento entre cartório e funcionário & 7 & 25,93 & 15 & 55,56 & 5 & 18,52 & 27 & 100 \\
\hline Relações pessoais no trabalho & 4 & 14,81 & 18 & 66,67 & 5 & 18,52 & 27 & 100 \\
\hline Retorno sobre o investimento & 4 & 14,81 & 18 & 66,67 & 5 & 18,52 & 27 & 100 \\
\hline Relacionamento na equipe & 7 & 25,93 & 15 & 55,56 & 5 & 18,52 & 27 & 100 \\
\hline Foco em resultados & 12 & 44,44 & 10 & 37,04 & 5 & 18,52 & 27 & 100 \\
\hline Comunicação na organização & 5 & 18,52 & 17 & 62,96 & 5 & 18,52 & 27 & 100 \\
\hline
\end{tabular}

Fonte: Elaborado pelas autoras.

Revista Administração em Diálogo

ISSN 2178-0080

Programa de Estudos Pós-Graduados em Administração

Pontifícia Universidade Católica de São Paulo 
Diante dos dois treinamentos aplicados no cartório, o Quadro I4 apresenta a opinião dos colaboradores em relação ao grau de interesse de cada um deles pelos programas de treinamento que participou. Em relação ao treinamento "Normas da Corregedoria", 48,I5\% dos colaboradores apontaram como um treinamento "muito interessante", enquanto 29,63\% apontaram como "interessante". Em relação ao treinamento "Prática no Direito Registral Imobiliário", 48,I5\% dos colaboradores também apontaram o programa como “muito interessante", enquanto 33,33\% afirmaram que o grau de interesse foi "interessante".

Verifica-se que no geral, ambos os programas atingiram um bom índice quando se refere ao interesse que eles despertaram nos colaboradores.

Quadro I4- Grau de interesse dos colaboradores pelos programas de treinamento

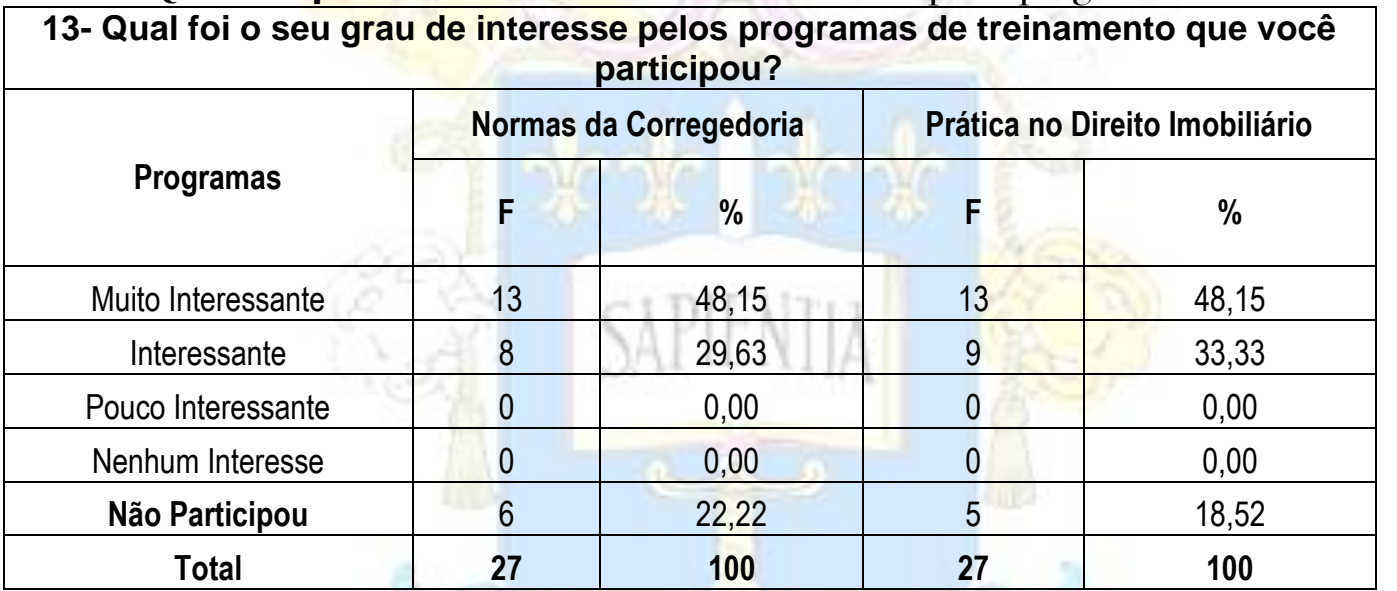

Fonte: Elaborado pela autora

Diante dos dois treinamentos aplicados no cartório, o Quadro I5 apresenta a opinião dos colaboradores em relação aos objetivos propostos pelos programas de treinamento que cada um deles participou. Em relação ao treinamento "Normas da Corregedoria", 5,, $85 \%$ dos colaboradores apontaram que as metas foram atingidas parcialmente, enquanto $25,93 \%$ apontaram que as metas foram atingidas plenamente. Em relação ao treinamento "Prática no Direito Registral Imobiliário”, 70,37\% dos colaboradores apontaram que as metas foram atingidas parcialmente enquanto II,II\% afirmaram que as metas foram atingidas plenamente. 
Nota-se que no geral, ambos os programas atingiram um bom índice quando se refere em atingir as metas propostas pelos treinamentos.

Quadro I5- Índice de metas atingidas pelos programas de treinamento

\begin{tabular}{|c|c|c|c|c|}
\hline \multicolumn{3}{|c|}{$\begin{array}{c}\text { 14- Em relação aos objetivos propostos pelos programas de treinamento que } \\
\text { você participou, mostre como as metas foram atingidas, considerando uma } \\
\text { escala de 1 a 3: }\end{array}$} \\
\hline \multirow{2}{*}{ Programas } & \multicolumn{3}{|c|}{$\begin{array}{c}\text { Normas da Corregedoria } \\
\text { F }\end{array}$} & Frática no Direito Imobiliário \\
\cline { 2 - 5 } & F & F & $\%$ \\
\hline 1 - Não foram atingidas & 0 & 0,00 & 0 & 0,00 \\
\hline 2- Foram atingidas parcialmente & 14 & 51,85 & 19 & 70,37 \\
\hline 3- Foram atingidas plenamente & 7 & 25,93 & 3 & 11,11 \\
\hline Não Participou & 6 & 22,22 & 5 & 18,52 \\
\hline Total & $\mathbf{2 7}$ & 100 & $\mathbf{2 7}$ & 100 \\
\hline
\end{tabular}

Fonte: Elaborado pelas autoras.

Diante dos dois treinamentos aplicados no cartório, o Quadro i6 apresenta a opinião dos colaboradores em relação ao conteúdo, duração e capacidade de gerar mudança referente aos programas de treinamento que cada um deles participou. Diante do treinamento "Normas da Corregedoria" 48,I5\% dos colaboradores apontaram o conteúdo como “ótimo" enquanto $29,63 \%$ apontaram como "bom”. Em relação à duração do treinamento, $55,56 \%$ apontaram como "bom" enquanto 22,22\% apontaram como "ótimo". Referente à capacidade de gerar mudança, 40,74\% dos colaboradores afirmaram como "bom" е пा,пा\% como "ruim". Diante do treinamento "Prática no Direito Registral Imobiliário”, 62,96\% dos colaboradores apontaram o conteúdo como "bom", enquanto 18,52\% apontaram como "ótimo". Em relação à duração do treinamento, 66,67\% apontaram como "bom", enquanto II,II\% apontaram como “ótimo". Referente à capacidade de gerar mudança, $55,56 \%$ dos colaboradores afirmaram como "bom" e 3,70\% como "ruim".

Nota-se que ambos os treinamentos alcançaram uma escala alta, pois, a opinião “ruim” foi o que obteve menor índice entre os itens avaliados. 
Quadro I6 - Opiniões sobre os programas de treinamento

\begin{tabular}{|c|c|c|c|c|c|c|c|}
\hline \multicolumn{8}{|c|}{ 15- Em relação aos programas de treinamento em uma escala de 1 a 3, dê sua opinião. } \\
\hline \multirow{2}{*}{ Normas da Corregedoria } & \multicolumn{2}{|c|}{ Conteúdo } & \multicolumn{3}{|c|}{ Duração } & \multicolumn{2}{|c|}{$\begin{array}{c}\text { Capacidade de Gerar } \\
\text { Mudança }\end{array}$} \\
\hline & $\mathbf{F}$ & $\%$ & $\mathrm{~F}$ & $\mathbf{F}$ & $\%$ & $\mathbf{F}$ & $\%$ \\
\hline 1 - Ruim & 0 & 0,00 & & 0 & 0,00 & 3 & 11,11 \\
\hline 2- Bom & 8 & 29,63 & & 15 & 55,56 & 11 & 40,74 \\
\hline 3- Ótimo & 13 & 48,15 & 6 & 6 & 22,22 & 7 & 25,93 \\
\hline Não Participou & 6 & 22,22 & & 6 & 22,22 & 6 & 22,22 \\
\hline Total & 27 & 100 & 1 & 27 & 100 & 27 & 100 \\
\hline \multirow{2}{*}{ Prática no Direito Imobiliário } & \multicolumn{2}{|c|}{ Conteúdo } & \multicolumn{3}{|c|}{ Duração } & \multicolumn{2}{|c|}{$\begin{array}{c}\text { Capacidade de Gerar } \\
\text { Mudança }\end{array}$} \\
\hline & $F$ & $\%$ & 20 & $\mathbf{F}$ & $\%$ & $\mathbf{F}$ & $\%$ \\
\hline 1 - Ruim & 0 & 0,00 & $2+1$ & 1 & 3,70 & 1 & 3,70 \\
\hline 2- Bom & 17 & 62,96 & 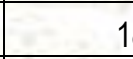 & 18 & 66,67 & 15 & 55,56 \\
\hline 3- Ótimo & 5 & 18,52 & $2=3$ & 3 & 11,11 & 6 & 22,22 \\
\hline Não Participou & 5 & 18,52 & & 5 & 18,52 & 5 & 18,52 \\
\hline Total & 27 & 100 & 2 & 27 & 100 & 27 & 100 \\
\hline
\end{tabular}

Fonte: Elaborado pela autora

Diante dos colaboradores pesquisados, o Quadro I7 apresenta a opinião dos colaboradores em relação ao grau de importância que o treinamento tem referente a vários tipos de competências. O item "aquisição de conhecimentos" e "competência pessoal" tiveram o maior índice com $88,89 \%$, enquanto o item "aumenta a empregabilidade" foi o qual teve menor índice com $22,22 \%$.

Nota-se que os colaboradores se importam em obter conhecimentos específicos e de qualificação profissional para que possam desenvolver melhor as suas atividades. 
Quadro 17 - Grau de importância do treinamento

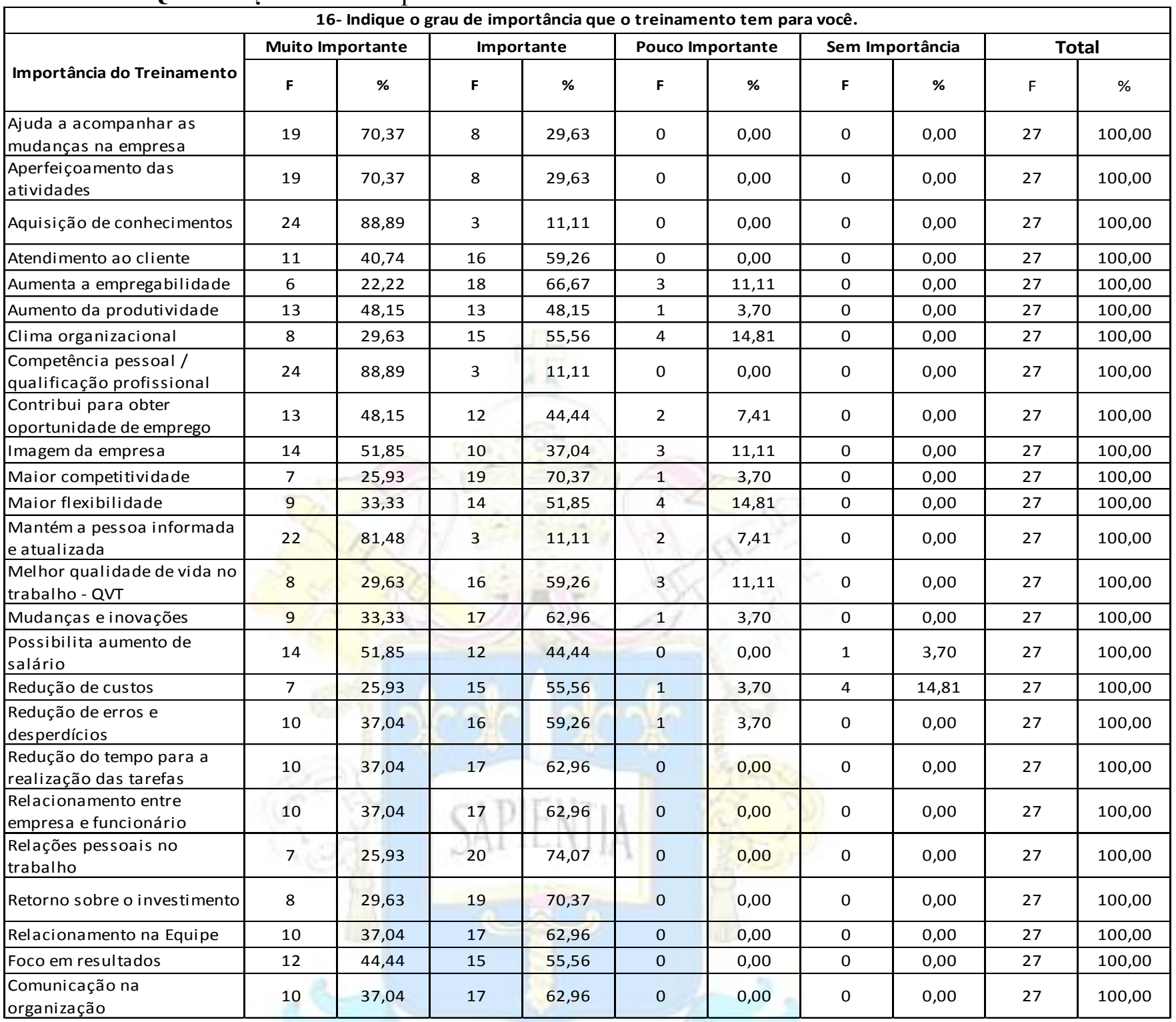

Fonte: Elaborado pelas autoras.

\section{Considerações Finais}

O objetivo geral deste estudo foi avaliar os programas de treinamento e desenvolvimento implantados no I $^{\circ}$ Oficial de Registro de Imóveis, Títulos e Documentos e Civil de Pessoa Jurídica de Piracicaba e mapear as competências desenvolvidas através dos treinamentos aplicados dentro da instituição prestadora de serviços públicos. Observa-se que o treinamento é de extrema importância para qualquer organização que deseja de devolver e desempenhar suas atividades com qualidade e garantia de satisfação dos clientes. 
Franco e Corrêa (2OII), comentam que o objetivo do treinamento é contribuir para a realização das metas gerais de uma empresa, onde as organizações associam o investimento no treinamento, ao crescimento da lucratividade e ao aumento da produtividade do colaborador.

Considerando as quatro fases de um programa de treinamento e desenvolvimento, a saber: diagnóstico, programação, execução e avaliação, este estudo considerou a última etapa do treinamento, a avaliação e apresentou os resultados dos programas de treinamentos desenvolvidos no cartório em estudo.

Nota-se que ambos os programas aplicados com os colaboradores do I ${ }^{\circ}$ Registro de Imóveis e Anexos de Piracicaba foram tidos como eficazes, uma vez, que os mesmos desenvolveram competências técnicas aos colaboradores participantes.

Através do questionário aplicado e considerando as respostas dos colaboradores pesquisados, observa-se que os índices apresentados no desenvolvimento das competências técnicas foram altos. Destaque para as competências "aperfeiçoamento das atividades", “aquisição de conhecimentos", "ajuda a acompanhar as mudanças do cartório", "qualificação profissional” e "mantém o colaborador informado e atualizado".

Tais competências garantem maior segurança jurídica aos clientes e também maior excelência na prestação de serviços, visto que, o registro imobiliário é um ramo muito complexo, exigindo do profissional desta área um conhecimento amplo sobre as normas e leis que regem este tipo de atividade.

Quanto às competências comportamentais, tais como "foco no resultado", "clima organizacional", "atendimento ao cliente" e entre outros, foram as quais apresentaram os menores índices. Como sugestão para estudos futuros, propõe-se a implantação de programas de treinamento que desenvolvam esse outro grupo de competências nos colaboradores do I ${ }^{\circ}$ Registro de Imóveis, Títulos e Documentos e Civil de Pessoa Jurídica de Piracicaba.

\section{Referências}

BOOG, Gustavo G. Manual de treinamento e desenvolvimento ABTD. São Paulo: MAKRON Books, I999. 3. Ed. 
CALDWELL, Charles M. Treinamento eficaz: um guia para o treinamento no trabalho. tradução e adaptação de José Henrique Lamensdorf. São Paulo: Siamar, 1988.

CATHO ON LINE. Disponível em

$<$ http://www3.catho.com.br/salario/action//artigos/Modelos_de_Habilidades_e_Competencias. php> Acesso em set. de 2 OI2.

CHIAVENATO, Idalberto Arão Sapiro. Recursos humanos o capital humano das organizações. São Paulo: Atlas, 2008. 8 Ed. 4. Reimpr.

DESSLER, Gary. Administração de recursos humanos. 2ed. São Paulo: Prentice Hall, 2003.

DUTRA, J. S. Gestão por competências: um modelo avançado para o gerenciamento de pessoas. São Paulo: Gente, 2OOI.

FERREIRA, A.B.H. Novo dicionário da língua portuguesa. Rio de Janeiro: Nova Fronteira, 1975.

FLEURY, Maria Tereza Leme. As pessoas na organização. São Paulo: Gente, 2002. 4 Ed.

FONTES, Lauro Barreto. Manual do treinamento da empresa moderna. São Paulo: Atlas, I980. 4 Ed ampl., refundida, atualizada.

FRANCO, Josy Roquete; CORREAA, Dalila Alves. Treinamento e Desenvolvimento nas Organizações. In: NOVAES NETTO, Arsênio; CORREAA, Dalila Alves. Pessoas nas Micro e Pequenas Empresas: Gestão e Processos. Itu:Ottoni, 2OII.

LAKATOS, E.M.; MARCONI, M.A. Fundamentos de metodologia científica. São Paulo: Atlas, I99I. 3. ed. rev. ampl.

LAKATOS, E.M.; MARCONI, M.A. Técnicas de pesquisas.5. ed. rev. ampl. São Paulo: Atlas, 2002.

LE BOTERF, G. De La competence- Essai surunattac teurétrange. Les Éditions D’ Organization. Quatrième tirage, Paris, 1995 .

LEME, Rogério. Seleção e Entrevista por Competência. Rio de Janeiro: Qualitymark, 2007.

MARRAS, Jean Pierrre. Administração de Recursos Humanos: do operacional ao estratégico. São Paulo: Futura, 2000. $3^{\text {a }}$ Ed.

MASCARENHAS, André Ofenhejm. Gestão Estratégica de Pessoas. São Cengage, 2008.

MCCLELLAND, D.C.: SPENCER, L.M. Competency assessment methods. history and state of the art. Boston Hay: McBer Research Press, I990.

ROCHA, Kátia Cristina Ferreira de. Competências e recursos: Um estudo exploratório desenvolvido com docentes do curso de administração de uma instituição de ensino superior. Dissertação de Mestrado Unimep, 2008.

ROESCH, Silvia Maria Azevedo. Projetos de estágio do curso de administração: guia para pesquisas, projetos, estágios e trabalhos de conclusão de curso. São Paulo: Atlas, I996.

WEBSTER 'S. Third new international dictionary of the english language, unabridged. Springfield, Massachusetts: G \& C. Merriam Co., I98I.

ZARIFIAN, P. Objectif compétence. Paris: Liaisons, I999. 